\title{
Carotid Endarterectomy Versus Stenting: A Meta-Analysis of Randomized Trials
}

\author{
Daniel Yavin, Derek J. Roberts, Michael Tso, Garnette R. Sutherland, \\ Misha Eliasziw, John H. Wong
}

\begin{abstract}
Background: A meta-analysis of randomized controlled trials (RCTs) was conducted to update the available evidence on the safety and efficacy of carotid endarterectomy (CEA) versus carotid artery stenting (CAS) in the treatment of carotid artery stenosis. Methods: A comprehensive search was performed of MEDLINE, EMBASE, CENTRAL, bibliographies of included articles and past systematic reviews, and abstract lists of recent scientific conferences. For each reported outcome, a Mantel-Haenszel random-effects model was used to calculate odds ratios (ORs) and $95 \%$ confidence intervals (CI). The $\mathrm{I}^{2}$ statistic was used as a measure of heterogeneity. Results: Twelve RCTs enrolling 6,973 patients were included in the meta-analysis. Carotid artery stenting was associated with a significantly greater odds of periprocedural stroke (OR 1.72,95\% CI 1.20 to 2.47 ) and a significantly lower odds of periprocedural myocardial infarction (OR $0.47,95 \%$ CI 0.29 to 0.78 ) and cranial neuropathy (OR 0.08, 95\% CI, 0.04 to 0.16 ). The odds of periprocedural death (OR 1.11, 95\% CI 0.56 to 2.18), target vessel restenosis (OR 1.95, 95\% CI 0.63 to 6.06), and access-related hematoma were similar following either intervention (OR 0.60, 95\% CI 0.30 to 1.21). Conclusions: In comparison with CEA, CAS is associated with a greater odds of stroke and a lower odds of myocardial infarction. While the results our meta-analysis support the continued use of CEA as the standard of care in the treatment of carotid artery stenosis, CAS is a viable alternative in patients at elevated risk of cardiac complications.
\end{abstract}

RÉSUMÉ: Méta-analyse portant sur des essais cliniques randomisés comparant l'endartérectomie carotidienne à la mise en place d'une prothèse endovasculaire. Contexte : Nous avons effectué une méta-analyse portant sur des essais cliniques randomisés (ECR), contrôlés, afin de mettre à jour les données disponibles sur la sécurité et l'efficacité de l'endartérectomie carotidienne (EC) comparée à la mise en place d'une prothèse endovasculaire (PEV) dans le traitement de la sténose carotidienne. Méthode : Nous avons effectué une recherche extensive des bases de données MEDLINE, EMBASE, CENTRAL, de la bibliographie des articles ainsi repérés et des revues de littérature systématiques antérieures, et des listes de résumés de conférences scientifiques récentes. Nous avons utilisé un modèle de Mantel-Haenszel pour calculer les rapports de cotes (RC) et les intervalles de confiance à 95\% (IC). La statistique I2 a été utilisée pour mesurer l'hétérogénéité. Résultats : La méta-analyse porte sur I2 ECR incluant 6973 patients. La mise en place d'une prothèse endovasculaire était associée à un risque significativement plus élevé d'accident vasculaire cérébral périprocédural (RC 1,72; IC à 95\% de 1,20 à 2,47) et à un risque significativement plus faible d'infarctus du myocarde périprocédural (RC 0,47 ;C à $95 \%$ de 0,29 à 0,78$)$ et de neuropathie crânienne (RC 0,08 ; IC à $95 \%$ de 0,04 à 0,16$)$. Les risques de décès périprocédural (RC 1,$11 ; \mathrm{IC}$ à $95 \%$ de 0,56 à 2,18$)$, de resténose de l'artère (RC 1,95 ; IC à $95 \%$ de 0,63 à 6,06$)$ et d'hématome reliés à la voie d'accès étaient semblables après l'une ou l'autre intervention (RC 0,60; IC 0,30 à 1,21). Conclusions : Comparée à l'EC, la PEV est associée à un risque plus élevé d'accident vasculaire cérébral et à un risque plus faible d'infarctus du myocarde. Bien que les résultats de notre méta-analyse soient en faveur de continuer à utiliser l'EC comme norme de soins dans le traitement de la sténose carotidienne, la PEV est une alternative valable chez les patients à risque élevé de complications cardiaques.

Can J Neurol Sci. 2011; 38: 230-235

Ischemic stroke is the leading cause of permanent disability in the developed world. ${ }^{1}$ Up to $20 \%$ of ischemic strokes result from atherosclerotic stenosis of the internal carotid artery. ${ }^{2}$ Carotid endarterectomy (CEA) has been shown to be of benefit in the treatment of symptomatic and asymptomatic carotid artery stenosis by several large randomized controlled trials (RCTs)..$^{3-7}$ Over the past decade, however, a growing interest has arisen in carotid artery stenting (CAS) as a less invasive means of carotid revascularization.

Disparate results have been reported by RCTs investigating the relative efficacy of CAS and CEA. ${ }^{8-23}$ Three trials were stopped prematurely after their interim analyses revealed an increased risk of stroke following CAS..$^{13,14,16,23}$ In contrast, six trials found CAS and CEA to have similar rates of periprocedural complications. ${ }^{9-11,17,18,22}$ As no single RCT has definitively established CAS to be either equivalent or superior to CEA, their relative safety and efficacy have been the subject of previous meta-analyses. ${ }^{6,24-29}$ Their findings, however, were

From the Division of Neurosurgery (DY, MT, GRS, JHW), Department of Clinical Neurosciences, Department of Surgery (DJR), Departments of Community Health Sciences and Oncology (ME), University of Calgary, Calgary, Alberta, Canada. Received September 21, 2010. Final Revisions Submitted October 21, 2010 Correspondence to: John H. Wong, 12th Floor, Division of Neurosurgery, 1403-29 Street NW, Foothills Medical Centre, Calgary, Alberta, T2N 2T9, Canada. 
limited by the presence of significant heterogeneity across reported outcomes.

The results of the Carotid Endarterectomy versus Stenting Trial (CREST), the largest RCT to date involving 2,502 patients, have recently been reported. ${ }^{30}$ We therefore conducted a metaanalysis of RCTs to update the available evidence on the safety and efficacy of CAS versus CEA in the treatment of carotid artery stenosis.

\section{Methods}

This meta-analysis adheres to the standards of the Preferred Reporting Items for Systematic Reviews and Meta-analyses (PRISMA) guidelines. ${ }^{31}$

\section{Search Strategy}

A comprehensive literature search was performed of MEDLINE (1966 to July 1, 2010), EMBASE (1977 to April 2010), and the Cochrane Central Register of Controlled Trials (CENTRAL) (1948 to April 2010) for RCTs comparing CEA and CAS. The following Medical Subject Headings terms and text words combined with the Boolean operator "OR" were employed in the search strategy: "carotid endarterectomy," "carotid artery stenting," and "carotid artery stenosis." Bibliographies of identified studies and previous systematic reviews on CAS and CEA were searched for additional trials not identified in the initial literature review. References were also identified by screening the abstract lists of the 2010 American Stroke Association meeting. One reviewer performed the search (D.Y.) while another assessed the results (D.J.R.).

\section{Study Selection}

Two reviewers (D.Y. and D.J.R.) independently screened identified abstracts and articles. Articles were selected if they met the following inclusion criteria: the study was a RCT comparing CEA to CAS, and the incidence of stroke, myocardial infarction, and death within 30 days were reported. Studies meeting our inclusion criteria were included in the analysis irrespective of the symptom status of enrolled patients, degree of carotid stenosis, setting of the trial, publication status, or written language of the report.

\section{Data Abstraction}

Two reviewers (D.Y. and D.J.R.) independently abstracted data from identified trials with any disagreements resolved by consensus or arbitration by a third reviewer (M.T.). Demographic information included the presence or absence of symptoms related to carotid artery stenosis, gender, age, and baseline degree of stenosis. Information pertaining to trial design included the number of patients randomized to each intervention, setting of the trial, number of study centres, duration of follow-up, and use of cerebral protection devices during CAS. Primary outcomes were the 30-day periprocedural rate of stroke, death, and myocardial infarction. Secondary outcomes included 30-day periprocedural rate of: disabling stroke; stroke or death; stroke, myocardial infarction or death, as well as the incidences of restenosis, cranial neuropathy, and access-related hematoma.

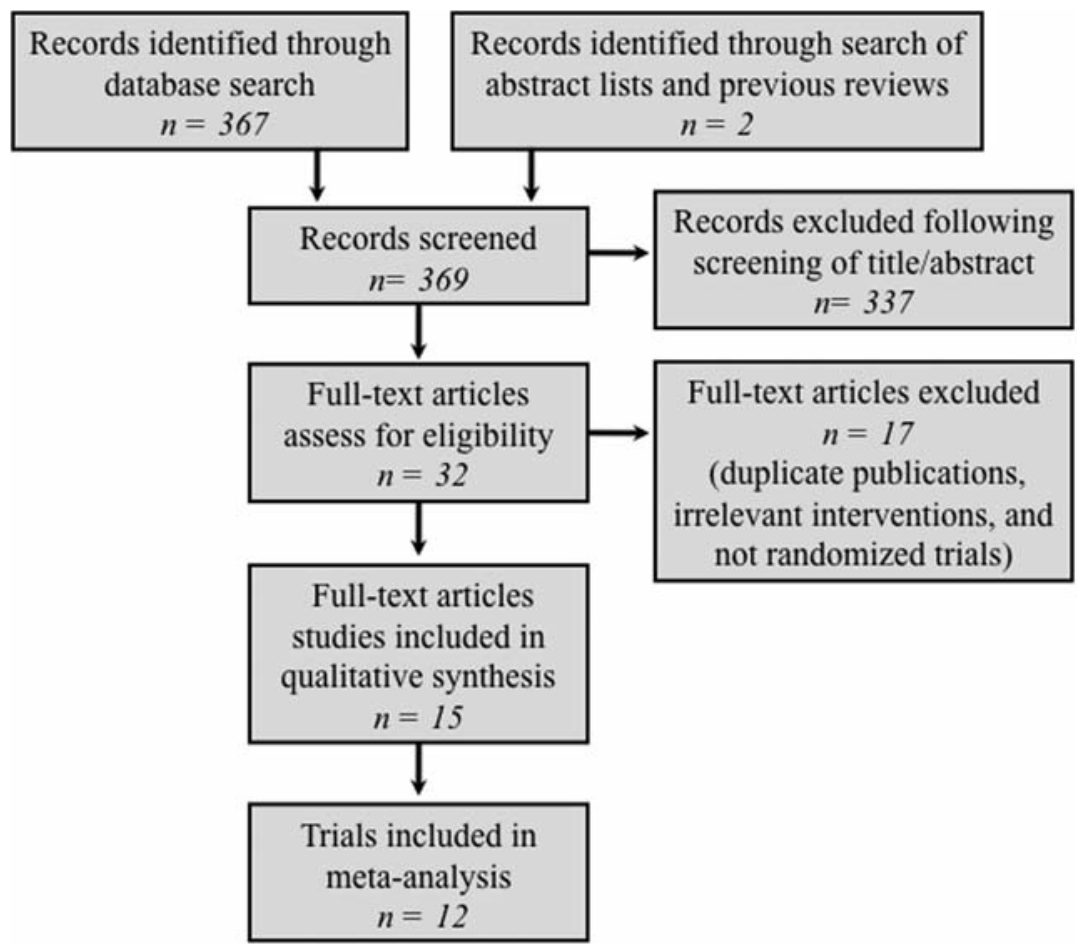

Figure 1: Selection of randomized trials evaluating carotid artery stenting and endarterectomy. 
Table: Characteristics of studies included in meta-analysis

\begin{tabular}{|c|c|c|c|c|c|c|c|}
\hline \multirow[t]{2}{*}{ Study (Year) } & \multirow[t]{2}{*}{ Design } & \multicolumn{2}{|c|}{ Participants } & \multirow{2}{*}{$\begin{array}{c}\text { Symptomatic/ } \\
\text { Asymptomatic (No. of } \\
\text { Patients) }\end{array}$} & \multirow{2}{*}{$\begin{array}{c}\text { Age } \\
\text { (Years) }\end{array}$} & \multirow{2}{*}{$\begin{array}{l}\text { Stenosis } \\
(\%)\end{array}$} & \multirow{2}{*}{$\begin{array}{l}\text { Duration of Follow-up } \\
\text { (Months) }\end{array}$} \\
\hline & & CAS & CEA & & & & \\
\hline Naylor $(1998)^{16}$ & $\mathrm{SC}, \mathrm{RCT}$ & 11 & 12 & $23 / 0$ & 68 & 82 & 1 \\
\hline Brooks $(2001)^{9}$ & $\mathrm{SC}, \mathrm{RCT}$ & 53 & 51 & $104 / 0$ & 66 & 85 & 24 \\
\hline Wallstent $(2001)^{23}$ & $\mathrm{MC}, \mathrm{RCT}$ & 107 & 112 & $219 / 0$ & 67 & 75 & 12 \\
\hline Brooks $(2004)^{10}$ & $\mathrm{SC}, \mathrm{RCT}$ & 43 & 43 & $0 / 85$ & 67 & 86 & 48 \\
\hline SAPPHIRE (2004) ${ }^{17 ; 18}$ & $\mathrm{MC}, \mathrm{RCT}$ & 167 & 167 & $96 / 238$ & 73 & NR & 36 \\
\hline SPACE $(2006)^{19 ; 20}$ & $\mathrm{MC}, \mathrm{RCT}$ & 607 & 589 & $1,196 / 0$ & 68 & NR & 24 \\
\hline TECAS-C $(2006)^{22}$ & $\mathrm{MC}, \mathrm{RCT}$ & 82 & 84 & NR & 63 & NR & 6 \\
\hline BACASS $(2008)^{8}$ & $\mathrm{SC}, \mathrm{RCT}$ & 10 & 10 & $20 / 0$ & 69 & 83 & 48 \\
\hline EVA-3S $(2008)^{13 ; 14}$ & $\mathrm{MC}, \mathrm{RCT}$ & 265 & 262 & $527 / 0$ & 69 & NR & 48 \\
\hline Steinbauer $(2008)^{21}$ & $\mathrm{SC}, \mathrm{RCT}$ & 43 & 44 & $87 / 0$ & 68 & 85 & 96 \\
\hline $\operatorname{ICSS}(2010)^{15}$ & $\mathrm{MC}, \mathrm{RCT}$ & 858 & 857 & $1,715 / 0$ & 70 & NR & 36 \\
\hline CREST $(2010)^{30}$ & $\mathrm{MC}, \mathrm{RCT}$ & 1,262 & 1,240 & $1,326 / 1,196$ & 69 & NR & 48 \\
\hline
\end{tabular}

CAS: carotid artery stenting; CEA: carotid endarterectomy; SC: single centre; RCT: randomized controlled trial.

\section{Statistical Analysis}

An intention-to-treat analysis was performed using Review Manager 5.0 software. To accommodate for inter-trial variability a random-effects model was employed to calculate odds ratios (ORs) and 95\% confidence intervals (CI). A $P$-value of $<0.05$ was considered a statistically significant difference between interventions. The $\mathrm{I}^{2}$ test was used to estimate the inter-trial variance due to underlying differences in design, patients, and interventions (heterogeneity). Values of $25 \%, 50 \%$, and $75 \%$ were classified as low, moderate, and high degrees of heterogeneity, respectively, with a $P$-value of $<0.1$ considered a statistically significant degree of heterogeneity. ${ }^{32}$ A sensitivity analysis was conducted to evaluate the effect of individual studies on the summary OR. Individual studies were removed one at a time from analyses and the summary OR was then recalculated.

\section{ReSUlts}

Fifteen reports of 12 RCTs enrolling a total of 6,973 patients were identified in our literature review and included in the metaanalysis (Figure 1). Trial characteristics are presented in the Table.

One RCT identified in our literature search, the Carotid and Vertebral Artery Transluminal Angioplasty Study (CAVATAS), was excluded. In this trial, stents were placed in only $26 \%$ of study participants randomized to endovascular intervention while balloon angioplasty alone was performed in the remainder. ${ }^{11}$ We consider balloon angioplasty and balloon angioplasty followed by stenting to be distinct interventions with the former not reflective of current practice.

\section{Primary Outcomes}

The incidence of 30-day periprocedural stroke was reported by ten studies randomizing 6,667 patients. ${ }^{8-10,13-20,22,30}$ The pooled odds of periprocedural stroke was significantly higher following CAS (OR 1.72, 95\% CI 1.20 to 2.47, $P=0.003$; Figure 2). A moderate degree of heterogeneity between studies was present $\left(\mathrm{I}^{2}=37 \%, P=0.14\right)$. The elevated periprocedural odds of stroke remained significant when our analysis was restricted to the eight trials enrolling exclusively patients with symptomatic carotid artery stenosis (OR 2.68, 95\% CI 1.18 to 6.11, $\left.P=0.02, \mathrm{I}^{2}=74 \%, P=0.001\right) .^{8,9,13-16,19-21,30}$ The odds of periprocedural stroke among patients with asymptomatic carotid artery stenosis were similar in the aggregated outcomes of two studies (OR $1.88,95 \%$ CI 0.79 to $4.46, P=0.15) \cdot{ }^{10,30}$ In a sensitivity analysis the odds of periprocedural stroke remained significantly in favour of CEA when data from any single trial was omitted.

Eight studies with a total of 5,448 patients contributed to our analysis of 30-day periprocedural myocardial infarction. ${ }^{8-10,13-}$ $15,17,18,22,30$ The pooled odds of myocardial infarction was significantly less for those undergoing CAS (OR 0.47, 95\% CI 0.29 to $0.78, P=0.003$; Figure 2 ). The elevated odds of myocardial infarction following CEA was observed consistently across trials without evidence of heterogeneity $\left(\mathrm{I}^{2}=0 \%, P=\right.$ 0.99). Exclusion of the reported outcomes of the CREST trial resulted in a loss of significance, although the OR was virtually identical (OR $0.48,95 \%$ CI 0.22 to $1.07, P=0.07, \mathrm{I}^{2}=0 \%, P=$ $0.97)$.

The 30-day periprocedural pooled odds of death was near unity when outcomes from 11 trials involving 4,252 participants were aggregated (OR $1.11,95 \%$ CI 0.56 to $2.18, P=0.76, \mathrm{I}^{2}=$ $1 \%, P=0.41$; Figure 2). ${ }^{8-10,13-22}$ The summary OR of 30 -day periprocedural death was not dependent on the results of any single trial.

\section{Secondary Outcomes}

The composite pooled odds of 30-day periprocedural stroke, death, or myocardial infarction were similar between CAS and CEA in an analysis of seven trials enrolling a total of 5,363 patients (OR $1.15,95 \% \mathrm{CI} 0.73$ to $1.82, P=0.55$; Figure 2). $8,9,13,14,17,18,22,30$ A moderate degree of heterogeneity was present $\left(\mathrm{I}^{2}=55 \%, P=0.04\right)$. These results did not vary with the omission of any one trial. The 30-day periprocedural pooled odds of disabling stroke was elevated following CAS among ten trials of 6,715 patients (OR $1.46,95 \%$ CI 0.97 to $2.19, P=0.07$, $\left.\mathrm{I}^{2}=3 \%, P=0.40\right) .^{8-10,13-20,23,30}$ This finding reached statistical 


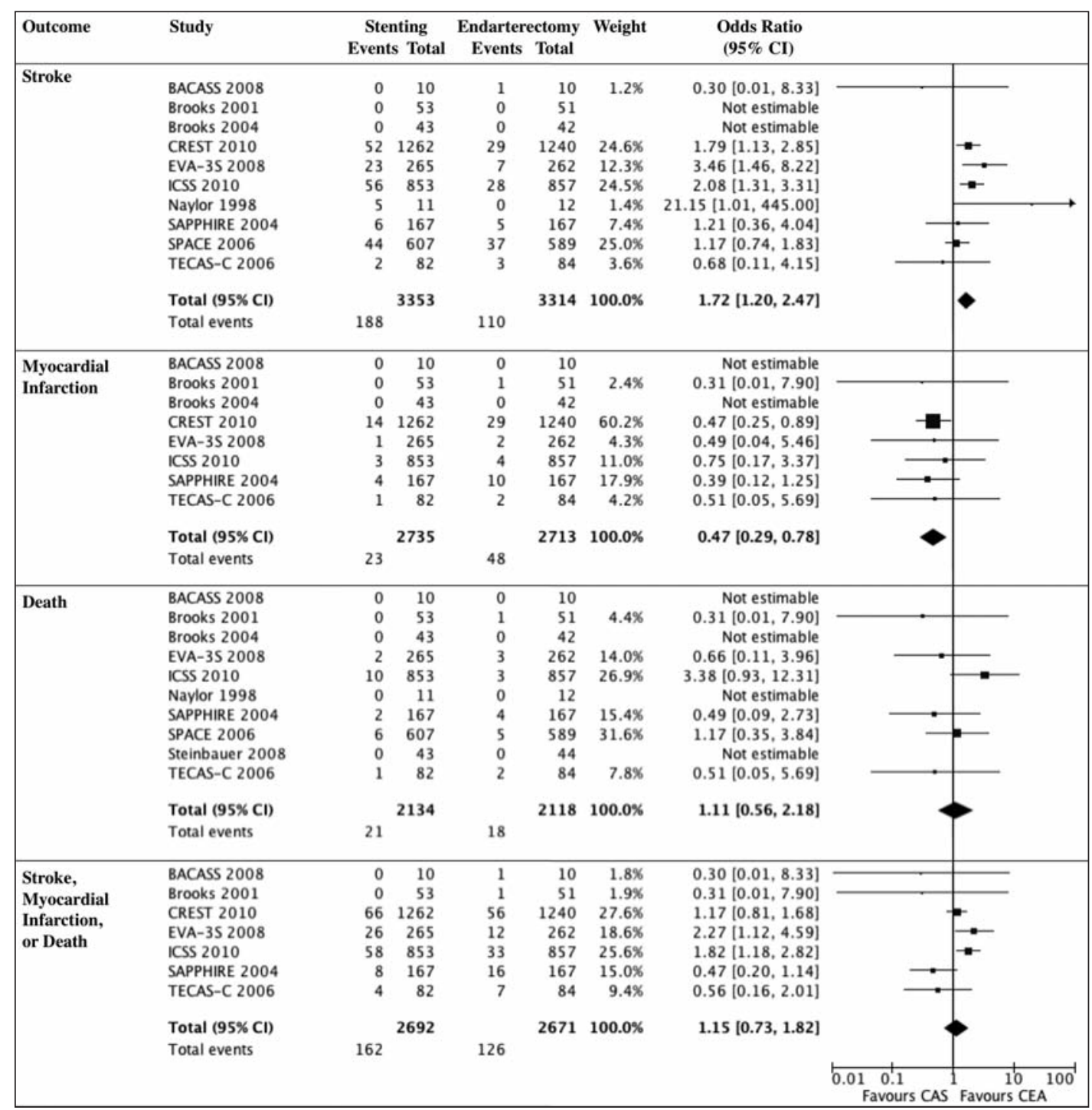

Figure 2: 30-day periprocedural outcomes. CAS: carotid artery stenting; CEA: carotid endarterectomy; CI: confidence interval

significance when the results of the ICSS trial were excluded (OR $1.68,95 \%$ CI 1.02 to $2.77, P=0.04, \mathrm{I}^{2}=4 \%, P=0.39$ ). The composite pooled odds of 30-day periprocedural stroke or death significantly favoured CEA when the outcomes of nine trials involving 4,218 patients were analyzed (OR 1.67, 95\% CI 1.05 to $\left.2.65, P=0.03, \mathrm{I}^{2}=47 \%, P=0.07\right) \cdot{ }^{8-10,13-20,23}$ Exclusion of the EVA-3S or ICSS trials resulted in a loss of significance in the composite odds of 30-day periprocedural of stroke or death (OR $1.51,95 \% \mathrm{CI}$ of 0.90 to $2.56, P=0.12, \mathrm{I}^{2}=48 \%, P=0.08$ and OR $1.56,95 \%$ CI of 0.86 to $2.86, P=0.14, \mathrm{I}^{2}=48 \%, P=0.08$, respectively). The composite outcome of stroke or death no longer differed at 24-months when the results of two trials randomizing a combined 1,207 patients were aggregated (OR $1.06,95 \% \mathrm{CI}$ of 0.71 to $\left.1.57, P=0.78, \mathrm{I}^{2}=0 \%, P=0.46\right){ }^{8,19,20}$

Rates of restenosis of the revascularized carotid artery were examined by seven trials enrolling a total of 1,678 patients. ${ }^{8-}$
10,13,14,17,18,21,22 The pooled odds of restenosis did not differ significantly between interventions (OR $1.95,95 \%$ CI 0.63 to $\left.6.06, P=0.25, \mathrm{I}^{2}=67 \%, P=0.03\right)$. Censoring of the results of the SAPPHIRE trial resulted in a significant difference in the rates of restenosis in favour of CEA (OR 2.68, 95\% CI 1.64 to 4.37, $\left.P=<0.0001, \mathrm{I}^{2}=0 \%, P=0.49\right)$.

The odds of cranial neuropathy was greater following CEA in an analysis of ten trials of 5,558 patients (OR $0.08,95 \%$ CI 0.04 to $\left.0.16, P<0.00001, \mathrm{I}^{2}=0 \%, P=0.99\right) .{ }^{8-10,13-18,21,22,30}$ No single trial exerted a dominant effect on the pooled odds of cranial neuropathy. The odds of access-related cervical or femoral hematomas were equally frequent following either intervention in a comparison of six trials of 2,497 patients (OR $0.58,95 \% \mathrm{CI}$ 0.29 to $\left.1.17, P=0.13, \mathrm{I}^{2}=14 \%, P=0.32\right) .^{8-10,15,17,18,21}$ The exclusion of the results of either the Brooks 2001 or Steinbauer 2008 trials resulted in the odds of access-related hematomas 
reaching significance in favour of CAS (OR $0.55,95 \% \mathrm{CI}$ of 0.35 to $0.85, P=0.007, \mathrm{I}^{2}=0 \%, P=0.48$ and OR $0.61,95 \% \mathrm{CI}$ 0.39 to $0.96, P=0.03, \mathrm{I}^{2}=0 \%, P=0.38$, respectively).

\section{Discussion}

Following its initial description in 1954, CEA has become the subject of more study than any other surgical intervention. ${ }^{33}$ The well-established role of CEA in the treatment of carotid artery stenosis has come into question following the advent of CAS. This is reflected by the fall in the rate of CEA by a third and the accompanying four-fold rise in the rate of CAS over the past decade. ${ }^{34}$ However, the widespread adoption of CAS has been based largely on observational studies reporting rates of stroke and death similar to that of CEA. ${ }^{35-37}$ To date, no single large RCT has convincingly established CAS to be equivalent to CEA. Moreover, several trials have found increased rates of complications following CAS. ${ }^{13-16,21,23}$ To update the available evidence on the comparative safety and efficacy of CAS and CEA, we have conducted the largest meta-analysis to date with pooled outcomes from 12 RCTs.

We found CAS to be associated with a significantly increased odds of 1.72 of periprocedural stroke. This finding may reflect an excess of non-disabling stroke among patients randomized to CAS as the increased odds of 1.46 of disabling stroke following CAS was not statistically significantly. Alternatively, the existing RCTs may have lacked sufficient power to detect a significant difference due to the relative infrequency of disabling stroke when compared to all forms of stroke. As the single goal of carotid revascularisation is to prevent future stroke, the elevated periprocedural risk of stroke associated with CAS must be taken into account when evaluating the long-term risk-benefit ratio of the procedure.

We found no difference in the overall periprocedural odds of death between CAS and CEA. This can likely be accounted for the balancing effect produced by each procedures' differing and competing odds of fatal periprocedural stroke and myocardial infarction. While CEA resulted in a significant decrease in the periprocedural odds of fatal stroke, this mortality benefit appears to have been offset by the increased odds of fatal myocardial infarction. The resulting morbidity may not be equivalent however, as periprocedural stroke has been found to have a greater adverse impact than myocardial infarction on a broad range of quality-of-life measures. ${ }^{30}$ The differing risks of myocardial infarction between CAS and CEA may allow the method of carotid revascularisation to be tailored to the patients' underlying risk for periprocedural cardiac events. In the absence of clinically significant risk factors predictive of a cardiac event, the results of our analysis support the continued use of CEA as the standard of care in the treatment of carotid stenosis.

Not surprisingly, our analysis revealed a greater than 10 -fold increase in the odds of cranial neuropathy with CEA. The odds of access-related hematoma, however, did not vary significantly between interventions. The increased rate of cranial neuropathy is an expected consequence of surgical exposure that is often transient, with a complete or partial functional recovery within six months in the majority of cases. ${ }^{38}$ The morbidity resulting from access-related hematoma was also limited as only a small minority of patients with cervical or femoral hematomas required further intervention and few access-related hematomas resulted in permenant disability or death in trials included in our analysis.

The odds of target vessel restenosis following either intervention were found to be similar. The consequence of this comparison was limited by the presence of a moderate heterogeneity as well as a wide ranging confidence interval (95\% CI 0.63 to 6.06). Outcomes reported by the SAPPHIRE trial were found to exert a dominant effect in our sensitivity analysis. Their exclusion resulted in a reduced odds of restenosis following CEA. It is unclear if this resulted from differences in the methodology, patient population, or the experience of interventionalists and surgeons participating in the SAPPHIRE trial. More long-term outcomes are required before meaningful conclusions on the comparative efficacy of CEA and CAS in preventing target vessel restenosis can be made.

Significant heterogeneity limited the implications of our comparisons of the rates of restenosis, death or stroke, stroke among patients with symptomatic stenosis, and the combined outcome of death, stroke, or myocardial infarction. Potential contributors of heterogeneity among reported outcomes included varying inclusion criteria across trials such as the enrolment of patients with asymptomatic carotid stenosis. Heterogeneity also resulted from the inclusion in our analysis of five trials which were prematurely terminated for reasons of futility, inadequate enrolment, and harm. ${ }^{13,14,16-20,23}$ Premature trial termination has been cited as a potential source of bias due to a systematic overestimate of treatment effect. ${ }^{28,39}$ A repeated analysis removing the outcomes of prematurely terminated trials resulted in the absence of significant heterogeneity in all of the above mentioned comparisons with $\mathrm{I}^{2}$ values of $0 \%(P=0.37), 21 \%(P$ $=0.28)$, and $31 \%(P=0.22)$ for rates of restenosis, death or stroke, and death, stroke, or myocardial infarction, respectively. The exclusion of prematurely terminated trials did not however significantly alter the results of the comparisons in our primary outcomes of stroke (OR 1.84, 95\% CI 1.33 to $2.53, P=0.0002$, $\left.\mathrm{I}^{2}=0 \%, P=0.46\right)$, myocardial infarction (OR $0.50,95 \%$ CI 0.28 to $\left.0.87, P=0.02, \mathrm{I}^{2}=0 \%, P=0.94\right)$, and death (OR $1.30,95 \%$ CI 0.28 to $\left.6.05, P=0.68, \mathrm{I}^{2}=35 \%, P=0.21\right)$.

The wide ranging prerequisite experience required of interventionalists between trials as well as the learning curve inherent to a new intervention such as CAS has been cited as a potential source of inter-trial variability and bias against CAS in published RCTs. ${ }^{40,41}$ Surprisingly, interventionalists' experience did not correlate with complication rates in sub-group analyses of the EVA-3S and ICSS trials. ${ }^{15,42}$ We found no evidence of a significant improvement in CAS performance over time as the aggregated periprocedural risk of stroke remained significantly elevated following CAS in analysis restricted to the five most recently published trials (OR $1.77,95 \%$ CI 1.22 to $2.56, P=$ $\left.0.003, \mathrm{I}^{2}=44 \%, P=0.13\right) .8,13-15,19,20,30$

\section{Conclusions}

The results of this meta-analysis support continued use of CEA as the standard of care in the treatment of carotid artery stenosis for the prevention of stroke. For those at high risk for cardiac complications, CAS may offer a viable alternative given its lower associated risk of myocardial infarction. Further epidemiological research would benefit clinicians in tailoring methods of carotid revascularization to specific patient subgroups. 


\section{REFERENCES}

1. American Heart Association. Heart disease and stroke statistics 2010 update. American Heart Association. Dallas; 2010.

2. Fairhead J, Rothwell P. The need for urgency in identification and treatment of symptomatic carotid stenosis is already established. Cerebrovasc Dis. 2005; 19(6):355-8.

3. North American Symptomatic Carotid Endarterectomy Trial Collaborators. Beneficial effect of carotid endarterectomy in symptomatic patients with high-grade carotid stenosis. N Engl J Med. 1991; 325(7):445-53.

4. Farrell B, Fraser A, Sandercock P, et al. Randomised trial of endarterectomy for recently symptomatic carotid stenosis: final results of the MRC European Carotid Surgery Trial (ECST). Lancet. 1998; 351(9113):1379-87.

5. Mayberg M, Wilson E, Lanzino G, et al. Carotid endarterectomy and prevention of cerebral ischemia in symptomatic cartoid stenosis. JAMA. 1991; 266(23):3289-94.

6. Goldstein L, Hasselblad V, Matcher D, et al. Comparison and metaanalysis of randomized trials of endarterectomy for symptomatic carotid artery stenosis. Neurology. 1995; 45(11): 1965-70.

7. Executive Committee for the Asymptomatic Carotid Atherosclerosis Study. Endarterectomy for asymptomatic carotid artery stenosis. JAMA. 1995; 273(18):1421-8.

8. Hoffmann A, Engelter S, Taschner C, et al. Carotid artery stenting versus carotid endarterectomy - a prospective randomised controlled single-centre trial with long-term follow-up (BACASS). Schweiz Arch Neurol Psychiatr. 2008; 159(2):84-9.

9. Brooks W, McClure R, Jones M, et al. Carotid angioplasty and stenting versus carotid endarterectomy: randomized trial in a community hospital. J Am Coll Cadiol. 2001; 38(6):1589-95.

10. Brooks W, McClure R, Jones M, et al. Carotid angioplasty and stenting versus carotid endarterectomy for treatment of asymptomatic carotid stenosis: a randomized trial in a community hospital. Neurosurgery. 2004; 54(2):318-24.

11. CAVATAS investigators. Endovascular versus surgical treatment in patients with carotid stenosis in the Carotid and Vertebral Artery Transluminal Angioplasty Study (CAVATAS): a randomised trial. Lancet. 2001; 357(9270):1729-37.

12. Ederle J, Bonati L, Dobson J, et al., on behalf of CAVATAS investigators. Endovascular treatment with angioplasty or stenting versus endarterectomy in patients with carotid artery stenosis in the Carotid And Veretebral Artery Transluminal Angioplasty Study (CAVATA): long-term follow-up of a randomized trial. Lancet Neurol. 2009; 8(10):898-907.

13. Mas J, Trinquart L, Leys D, et al. Endarterectomy versus angioplasty in patients with symptomatic severe carotid stenosis (EVA-3S) trial: results up to 4 years from a randomized, multicentre trial. Lancet Neurol. 2008; 7(10):885-92.

14. Mas J, Chatellier G, Beyssen B, et al. Endarterectomy versus stenting in patients with symptomatic severe carotid stenosis. N Engl J Med. 2006; 355(16):1660-71

15. International Carotid Stenting Study investigators. Carotid artery stenting compared with endarterectomy in patients with symptomatic carotid stenosis (International Carotid Stenting Study): an interim analysis of a randomised controlled trial. Lancet. 2010; 375(9719):985-97.

16. Naylor A, Bolia A, Abbott R, et al. Randomized study of carotid angioplasty and stenting versus carotid endarterectomy: a stopped trial. J Vasc Surg. 1998; 28(2):326-34.

17. Gurm H, Yadav J, Fayad P, et al. Long-term results of carotid stenting versus endarterectomy in high-risk patients. $\mathrm{N}$ Engl $\mathrm{J}$ Med. 2008; 358(15):1572-9.

18. Yadav J, Wholey M, Kuntz R, et al. Protected carotid-artery stenting versus endarterectomy in high-risk patients. N Engl J Med. 2004; 351(25):1493-501.

19. Eckstein H, Ringleb P, Allenberg J, et al. Results of the StentProtected Angioplasty versus Carotid Endarterectomy (SPACE) study to treat symptomatic stenoses at 2 years: a multinational, prospective, randomised trial. Lancet Neurol. 2008; 7(10): 893-902.
20. Ringleb P, Allenberg J, Bruckmann H, et al. 30 day results from the SPACE trial of stent protected angioplasty versus carotid endarterectomy in symptomatic patients: a randomised noninferiority trial. Lancet. 2006; 368(9543):1239-47.

21. Steinbauer M, Pfister K, Greindl M, et al. Alert for increased longterm follow-up after carotid artery stenting: results of a prospective, randomized, single-center trial of carotid artery stenting vs carotid endarterectomy. J Vasc Surg. 2008; 48(1):93-8.

22. Ling F, Jiao L. Preliminary report of trial of endarterectomy versus stenting for the treatment of carotid atherosclerotic stenosis in China (TESCAS-C). Chinese J Cerebrovasc Dis. 2006: 1(3);4-8.

23. Alberts M. Results of a multicenter prospective randomized trial of carotid artery stenting vs carotid endarterectomy. Stroke. 2001; 32(1):325.

24. Ederle J, Featherstone R, Brown M. Randomized controlled trials comparing endarterectomy and endovascular treatment for carotid artery stenosis: a Cochrane systematic review. Stroke. 2009; 40(4):1373-80.

25. Meier P, Knapp G, Tamhane U, et al. Short term and intermediate term comparison of endarterectomy versus stenting for carotid artery stenosis: systematic review and meta-analysis of randomised controlled clinical trials. BMJ. 2010; 340:c467.

26. Murad MH, Flynn DN, Elamin MB, et al. Endarterectomy vs stenting for carotid artery stenosis: a systematic review and meta-analysis. J Vasc Surg. 2008; 48(2):487-93.

27. Ringleb P, Chatellier G, Hacke W, et al. Safety of endovascular treatment of carotid artery stenosis compared with surgical treatment: a meta-analysis. J Vasc Surg. 2008; 47(2):350-5.

28. Roffi M, Mukherjee D, Clair DG. Carotid artery stenting vs. endarterectomy. Eur Heart J. 2009; 30(22):2693-704.

29. Bakoyiannis C, Economopoulos KP, Georgopoulos S, et al. Carotid endarterectomy versus carotid angioplasty with or without stenting for treatment of cartid artery stenosis: an updated metaanalysis of randomized controlled trials. Int Angiol. 2010; 29(3) 205-15.

30. Brott TG, Hobson RW, Howard G, et al. Stenting versus endarterectomy for treatment of carotid-artery stenosis. N Engl J Med. 2010; 363(1)11-23.

31. Moher D, Liberati A, Tetzlaff J, et al. Preferred Reporting items for Systematic Reviews and Meta-Analyses: The PRISMA statement. Int J Surg. 2010; 8(5)336-41.

32. Higgins J, Thompson S, Deeks J, et al. Measuring inconsistency in meta-analysis. BMJ. 2003; 327(7414):557-60.

33. Eastcott H, Pichering G, Rob C. Reconstruction of internal carotid artery in a patient with intermittent attacks of right hemiplegia. Lancet. 1954; 267(6846):994-6.

34. Goodney P, Travis L, Malenka D, et al. Regional variation in carotid artery stenting and endarterectomy in the medicare population. Circ Cardiovasc Qual Outcomes. 2010; 3(1):15-24.

35. Diethrich E, Ndiaye M, Reid D. Stenting in the carotid artery: initial experience in 110 patients. J Endovasc Surg. 1996; 3(1):42-62.

36. Roubin $G$, New $G$, Iyer $S$, et al. Immediate and late clinical outcomes of carotid artery stenting in patients with symptomatic and asymptomatic carotid artery stenosis. Circulation. 2001; 103 (4):532-7.

37. Shawl FA. Carotid artery stenting: acute and long-term results. Curr Opin Cardiol. 2002; 17(6):671-6.

38. Ballotta E, Meldrum H, Elisziw M. Cranial nerve injuries after carotid endarterectomy: a prospective study. Surgery. 1999; 125 (1):85-91.

39. Goodman S. Stopping at nothing? Some dilemmas of data monitoring in clinical trials. Ann Intern Med. 2007; 146(12): 882-7.

40. Roffi M, Sievert H, Gray W, et al. Carotid artery stenting versus surgery: adequate comparisons? Lancet Neurol. 2010; 9(4): 339-41.

41. Wholey MH, Wholey M, Bergeron P, et al. Current global status of carotid artery stent placement. Cathet Cardiovasc Diagn. 1998; 44(1):1-6.

42. Mas J, Schatellier G. Endarterectomy versus stenting for carotid stenosis:authors reply. N Engl J Med. 2007; 356(3)306-7. 